\title{
Location of the Susceptibility Vessel Sign on T2*-Weighted MRI and Early Recanalization within 1 Hour after Tissue Plasminogen Activator Administration
}

\author{
Junya Aoki Kazumi Kimura Kensaku Shibazaki Yuki Sakamoto \\ Naoki Saji Junichi Uemura \\ Department of Stroke Medicine, Kawasaki Medical School, Kurashiki City, Japan
}

\section{Key Words}

Acute ischemic stroke $\cdot$ Susceptibility vessel sign $\cdot$ Thrombolysis

\begin{abstract}
Background: We have recently reported that the susceptibility vessel sign (SVS) at the proximal portion of the horizontal (M1) middle cerebral artery (MCA) on T2*-weighted MRI is a strong predictor for no early recanalization after intravenous recombinant tissue plasminogen activator (t-PA) therapy. However, it is unclear whether the presence of the SVS at other locations, such as distal M1, the vertical portion (M2) of the MCA, and distal branches (MCA distal), is a predictor for no early recanalization in acute ischemic stroke patients. Methods: The SVS was defined as a hypointense signal of the MCA on T2*-weighted MRI on admission. The locations of the SVS were classified as M1 proximal, M1 distal, and MCA distal. M1 proximal SVS was defined as an SVS at the origin of the M1. M1 distal SVS was any M1 SVS not including the origin of the M1. MCA distal SVS was an SVS further away from M1. Early recanalization was defined as a new appearance of at least one of the distal branches on MRA within $1 \mathrm{~h}$ after t-PA therapy. A good outcome at 3 months was defined as a modified Rankin Scale (mRS) score of 0-1. Results: Consecutive acute stroke patients admitted to our stroke center and treated with t-PA between October 2005 and October 2012 were enrolled. There were 158 patients [median age, 78 (71-84) years; 84 (53\%) males; median National Institutes of Health Stroke Scale score, 16 (10-20)]. Internal carotid artery occlusion was seen in 18 (72\%) of the 25 patients with M1 proximal SVS, in 3 (14\%) of the 22 patients with M1 distal SVS, in 4 (9\%) of the 44 patients with MCA distal SVS, and in 18 (27\%) of the 67 patients with No SVS ( $p<$ 0.001). Twenty-four (96\%) of the 25 patients with M1 proximal SVS had no early recanalization, while 16 (73\%) of the 22 patients with M1 distal SVS, 25 (57\%) of the 44 patients with MCA distal SVS, and 36 (54\%) of the 67 patients with No SVS had no early recanalization $(p<0.001$,
\end{abstract}


0.140 , and 0.846 , respectively, compared to the patients with No SVS). Multivariate analysis showed that only M1 proximal SVS was significantly associated with no early recanalization (odds ratio 16.80, 95\% confidence interval 2.04-138.17, $\mathrm{p}=0.009$ ). Among the 95 patients with a premorbid mRS score of $0-1$, none (0\%) of the 16 patients with M1 proximal SVS, 5 (36\%) of the 14 patients with M1 distal SVS, 12 (48\%) of the 25 patients with MCA distal SVS, and 13 (33\%) of the 40 patients with No SVS achieved a good outcome ( $p=0.011,1.000$, and 0.295 , respectively, compared to the patients with No SVS). Conclusion: M1 proximal SVS on T2*weighted MRI is a strong predictor for no early recanalization, and all patients with it had a poor outcome. However, M1 distal SVS and MCA distal SVS were not predictors for no early recanalization, and half of the patients had a poor outcome.

(C) 2013 S. Karger AG, Basel

\section{Introduction}

The aim of the intravenous recombinant tissue plasminogen activator (t-PA) therapy for acute stroke is to recanalize the occluded artery and reperfuse the penumbral tissue. Early recanalization, defined as recanalization during the first $1-2 \mathrm{~h}$ of t-PA therapy, is expected to triple or quadruple the favorable outcome rate [1-3]. In patients without early recanalization, intra-arterial intervention is a promising approach. The RECANALISE (Recanalisation Using Combined Intravenous Alteplase and Neurointerventional Algorithm for Acute Ischemic Stroke) study showed that combined t-PA therapy and intra-arterial intervention was associated with higher recanalization than t-PA alone, and a better outcome was associated with time from symptom onset to recanalization [4].

We have recently reported that the susceptibility vessel sign (SVS) seen on $\mathrm{T} 2{ }^{*}$-weighted MRI as a hypointense signal at the proximal portion of the horizontal (M1) middle cerebral artery (MCA) served as the only independent factor related to no early recanalization and a poor outcome [5, 6]. Thus, we considered that patients with M1 proximal SVS are exactly those who need immediate combined intravenous and intra-arterial treatment. In our previous reports, however, we did not evaluate the impact of the SVS at other locations, such as distal M1, the vertical portion (M2) of the MCA, and distal branches, on early recanalization and patient outcomes. Although some studies reported patients' characteristics and radiological findings based on different SVS sites [7], their effects on early recanalization and clinical outcome remain unknown.

The aim of the present study was to investigate, whether the impact of the SVS on early recanalization and patient outcomes differs based on their MCA location in patients treated with t-PA.

\section{Methods}

Consecutive patients with acute ischemic stroke and treated with t-PA admitted to our stroke center between October 2005 and October 2012 were prospectively enrolled; t-PA therapy was generally administered based on the Japan Alteplase Clinical Trial [8, 9]. In addition, in our hospital, acute ischemic stroke patients with unknown onset time were also treated with t-PA based on diffusion-weighted imaging (DWI)/fluid-attenuated inversion recovery (FLAIR) mismatch [10]. The interval from onset to t-PA therapy was automatically calculated as $180 \mathrm{~min}$ in those patients. Only patients with an occlusion of the internal carotid artery (ICA), M1, and M2 were enrolled in the present study. A single t-PA dose of $0.6 \mathrm{mg} / \mathrm{kg}$ (not exceeding $60 \mathrm{mg}$ ) was administered intravenously, with $10 \%$ given as a bolus, followed 
by a continuous infusion of the remainder of the dose over $1 \mathrm{~h}$. The institutional Review Board at the Kawasaki Medical School approved this study.

The following clinical information was obtained: age, sex, time from onset to treatment, neurological deficits, modified Rankin Scale (mRS) score before stroke, vascular risk factors, atrial fibrillation, past antithrombotic medication, blood pressure before intravenous thrombolysis, stroke etiology, and the presence of cardiac sources of emboli. Neurological deficits were assessed using the National Institutes of Health Stroke Scale (NIHSS) score before thrombolysis. Vascular risk factors were identified as: (1) hypertension, a history of using antihypertensive agents, a systolic blood pressure $\geq 140 \mathrm{~mm} \mathrm{Hg}$, or a diastolic blood pressure $\geq 90 \mathrm{~mm} \mathrm{Hg}$ at hospital discharge; (2) diabetes mellitus, the use of hypoglycemics, random glucose level $\geq 200 \mathrm{mg} / \mathrm{dl}$, or glycosylated hemoglobin $>6.4 \%$ on admission, and (3) hyperlipidemia, the use of antihyperlipidemic agents or serum cholesterol level $>220 \mathrm{mg} / \mathrm{dl}$. Medications taken before admission were also documented. Anticoagulation was performed using warfarin sodium. Aspirin, ticlopidine, clopidogrel, and cilostazol were given as antiplatelet therapy.

Stroke etiology was determined at hospital discharge using Trial of ORG 10172 in Acute Stroke Treatment criteria: (1) small-vessel occlusion, (2) large-artery atherosclerosis, (3) cardioembolism, or (4) other or undetermined etiology of stroke [11]. Duplex ultrasonography was performed in all patients to assess the common carotid artery and ICA. To determine the presence of cardiac sources of emboli, transcranial Doppler, transthoracic echocardiography, and Holter electrocardiography were also carried out. Transesophageal echocardiography and conventional cerebral angiography were performed if appropriate.

The MRI protocol included DWI, FLAIR, T2*-weighted MRI, and intracranial MRA, which were performed on a 1.5-tesla scanner (Signa EXCITE XL v. 11.0; GE Healthcare, Milwaukee, Wis., USA) on admission and $1 \mathrm{~h}$ after t-PA administration. DWI was obtained using the following parameters: repetition time (TR), 6,000 ms; echo time (TE), $78 \mathrm{~ms}$; b values, 0 and $1,000 \mathrm{~s} / \mathrm{mm}^{2}$; field of view, $24 \mathrm{~cm}$; acquisition matrix, $128 \times 192$, and slice thickness, $6.0 \mathrm{~mm}$ with a 1.0-mm gap. FLAIR sequences were obtained in the axial plane using the following parameters: TR, 8,002 ms; TE, $109 \mathrm{~ms}$; inversion time, 2,000 ms; field of view, $24 \mathrm{~cm}$; acquisition matrix, $256 \times 224$, and section thickness, $6.0 \mathrm{~mm}$ with a $1.0-\mathrm{mm}$ gap. T2*-weighted images were obtained using the following parameters: TR, $700 \mathrm{~ms}$; TE, $20 \mathrm{~ms}$; field of view, $24 \mathrm{~cm}$; acquisition matrix, $256 \times 192$, and section thickness, $6.0 \mathrm{~mm}$ with a $1.0-\mathrm{mm}$ gap. Time-of-flight MRA covered the circle of Willis with: TR, $25 \mathrm{~ms}$; TE, $6.9 \mathrm{~ms}$, and flip angle, $20^{\circ}$.

The SVS defined as a hypointense signal of the MCA on T2*-weighted MRI on admission was assessed by one vascular neurologist (J.A.) who was blinded to the clinical information. M1 proximal SVS was defined as an SVS at the origin of the M1. M1 distal SVS was any SVS not including the origin of the M1. MCA distal SVS was considered as an SVS further away from M1 (fig. 1). The Alberta Stroke Program Early CT Score on DWI on admission was also assessed. A semiquantitative evaluation using the Alberta Stroke Program Early CT Score on DWI has been shown to be a reproducible method similar to that on CT [12-14]. The infarct volume on the initial DWI was calculated using NIH image. First, the perimeter of the area of abnormal signal intensity was traced on each DWI image, and then the NIH image calculated the total volume using the thickness and the area delineated on the slice. The presence of recanalization was assessed using MRA $1 \mathrm{~h}$ after t-PA therapy. Recanalization was graded as complete, partial, or no recanalization as follows: (1) complete recanalization: reappearance of the entire occluded artery and distal branch of vessels; (2) partial recanalization: new appearance of at least one of the distal branches supplied by an occluded artery, and (3) no recanalization: persistent occlusion. For patients treated with intra-arterial intervention before follow-up MRI, digital subtraction angiography was used to assess recanalization. Early recanalization 


\section{Cerebrovascular \\ Diseases}

Fig. 1. Representative cases with an SVS at the proximal (a) and distal portions of the horizontal (M1) MCA (b), and at the distal portion of the MCA (c, d).

\begin{tabular}{l|l}
\hline Cerebrovasc Dis Extra 2013;3:111-120 \\
\hline DOI: $10.1159 / 000354848$ & $\begin{array}{l}\text { @ 2013 S. Karger AG, Basel } \\
\text { www.karger.com/cee }\end{array}$ \\
\hline
\end{tabular}

Aoki et al.: Location of the Susceptibility Vessel Sign on T2*-Weighted MRI and Early Recanalization within 1 Hour after Tissue Plasminogen Activator Administration
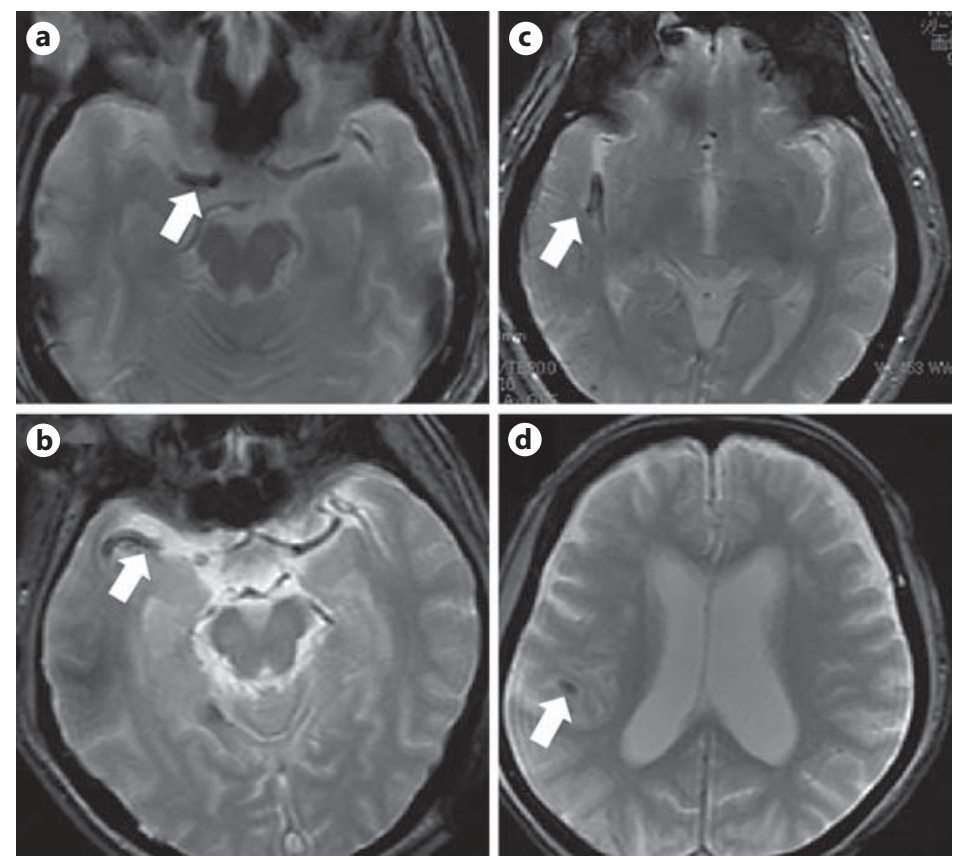

was evaluated before intra-arterial intervention started. Grade 2 and more according to the Thrombolysis in Cerebral Infarction grading system was defined as early recanalization [15].

At 3 months, the presence of a good outcome (mRS score, $0-1$ ) was assessed.

\section{Statistical Analysis}

First, all patients were classified into 4 groups based on the presence and location of the SVS as follows: (1) M1 proximal SVS, (2) M1 distal SVS, (3) MCA distal SVS, and (4) No SVS. Clinical, radiological, and laboratory findings were compared among the 4 groups. Second, all patients were divided into 2 groups based on the presence and absence of early recanalization. Multivariate logistic regression analysis was used to identify independent factors associated with early recanalization. Variables from univariate analyses with $\mathrm{p}$ values $<0.1$ were entered into the multivariate analysis. The relative risk of early recanalization was expressed as odds ratios with 95\% confidence intervals. After that, clinical outcomes were evaluated among the 4 groups. The Mann-Whitney $U$ test was used to analyze differences in continuous variables, and Fisher's exact test was used to analyze differences in categorical variables. The data are presented as median values (interquartile ranges) or frequencies (\%). All statistical analyses were performed using IBM SPSS Statistics for Windows version 19 software (Chicago, Ill., USA). Results were considered significant at $\mathrm{p}<0.05$.

\section{Results}

From October 2005 to October 2012, 266 patients were admitted to our hospital and treated with t-PA therapy. Of the 266 patients, 43 had ICA occlusion, 69 had M1 occlusion, and 46 had M2 occlusion. Thus, 158 patients [median age, 78 (71-84) years; 84 (53\%) males; median NIHSS score, 16 (10-20)] were enrolled into the present study. Of the 158 patients, $23(15 \%)$ underwent intra-arterial intervention, and of these 23 patients, the presence of early recanalization was assessed by digital subtraction angiography in 4 . 


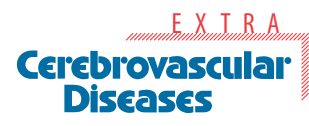

\begin{tabular}{l|l}
\hline \multicolumn{2}{l}{ Cerebrovasc Dis Extra 2013;3:111-120 } \\
\hline DOI: $10.1159 / 000354848$ & $\begin{array}{l}\text { C } 2013 \text { S. Karger AG, Basel } \\
\text { www.karger.com/cee }\end{array}$ \\
\hline Aoki et al.: Location of the Susceptibility Vessel Sign on T2*-Weighted MRI and Early
\end{tabular}

Aoki et al.: Location of the Susceptibility Vessel Sign on $12^{*}$-Weighted MRI and Ear
Recanalization within 1 Hour after Tissue Plasminogen Activator Administration

Table 1. Clinical characteristics and imaging findings based on the presence and location of the SVS

\begin{tabular}{|c|c|c|c|c|c|}
\hline Variables & $\begin{array}{l}\text { M1 proximal SVS } \\
(\mathrm{n}=25)\end{array}$ & $\begin{array}{l}\text { M1 distal SVS } \\
(\mathrm{n}=22)\end{array}$ & $\begin{array}{l}\text { MCA distal SVS } \\
(\mathrm{n}=44)\end{array}$ & $\begin{array}{l}\text { No SVS } \\
(\mathrm{n}=67)\end{array}$ & $\mathrm{p}$ \\
\hline Median age, years & $79(73-83)$ & $76(66-86)$ & $79(74-84)$ & $77(70-85)$ & 0.960 \\
\hline Male sex, $\mathrm{n}$ & $14(56)$ & $15(68)$ & $21(48)$ & $34(51)$ & 0.431 \\
\hline Median NIHSS score on admission & $20(15-23)$ & $17(12-22)$ & $13(7-19)$ & $16(10-20)$ & 0.001 \\
\hline Premorbid mRS score $0-1, \mathrm{n}$ & $20(75)$ & $18(82)$ & $32(73)$ & $49(73)$ & 0.771 \\
\hline Interval from onset to thrombolysis, min & $153(131-167)$ & $146(120-167)$ & $145(120-175)$ & $143(115-172)$ & 0.894 \\
\hline Intra-arterial intervention, $\mathrm{n}$ & $4(16)$ & $4(18)$ & $5(11)$ & $10(15)$ & 0.887 \\
\hline \multicolumn{6}{|l|}{ Vascular risk factor, $\mathrm{n}$} \\
\hline Hypertension & $11(44)$ & $14(64)$ & $34(77)$ & $47(70)$ & 0.037 \\
\hline Diabetes mellitus & $3(12)$ & $3(14)$ & $8(18)$ & $18(27)$ & 0.310 \\
\hline Hyperlipidemia & $3(12)$ & $6(27)$ & $9(21)$ & $15(22)$ & 0.608 \\
\hline Atrial fibrillation & $18(72)$ & $14(64)$ & $25(57)$ & $35(52)$ & 0.356 \\
\hline \multicolumn{6}{|l|}{ Past medication, $\mathrm{n}$} \\
\hline Antiplatelet therapy & $7(28)$ & $6(27)$ & $8(18)$ & $19(28)$ & 0.648 \\
\hline Anticoagulation therapy & $4(16)$ & $2(9)$ & $5(11)$ & $5(8)$ & 0.666 \\
\hline Median systolic blood pressure, mm Hg & $152(145-168)$ & $156(138-167)$ & $147(131-164)$ & $156(139-170)$ & 0.334 \\
\hline Median diastolic blood pressure, $\mathrm{mm} \mathrm{Hg}$ & $82(68-95)$ & $81(70-98)$ & $81(70-91)$ & $84(70-92)$ & 0.860 \\
\hline \multicolumn{6}{|l|}{ Stroke etiology, $\mathrm{n}$} \\
\hline Large-artery atherosclerosis & $4(16)$ & $3(14)$ & $2(5)$ & $7(10)$ & 0.430 \\
\hline Cardioembolism & $18(72)$ & $14(64)$ & $28(64)$ & $38(57)$ & 0.587 \\
\hline Other or undetermined & $3(12)$ & $5(23)$ & $14(32)$ & $22(33)$ & 0.205 \\
\hline \multicolumn{6}{|l|}{ Portion of occlusion, $\mathrm{n}$} \\
\hline ICA & $18(72)$ & $3(14)$ & $4(9)$ & $18(27)$ & $<0.001$ \\
\hline M1 & $7(28)$ & $19(86)$ & $17(39)$ & $26(39)$ & $<0.001$ \\
\hline M2 & $0(0)$ & $0(0)$ & $23(52)$ & $23(34)$ & $<0.001$ \\
\hline \multicolumn{6}{|l|}{ DWI findings } \\
\hline Median ASPECTS & $7(3-9)$ & $7(5-9)$ & $8(6-10)$ & $8(6-10)$ & 0.095 \\
\hline Median initial ischemic volume, $\mathrm{ml}$ & $12.3(4.0-56.3)$ & $13.2(2.1-42.2)$ & $4.1(1.0-21.5)$ & $7.1(1.6-35.8)$ & 0.091 \\
\hline \multicolumn{6}{|l|}{ Early recanalization } \\
\hline No & $24(96)$ & $16(73)$ & $25(57)$ & $36(54)$ & $<0.001$ \\
\hline Partial & $1(4)$ & $5(23)$ & $12(27)$ & $19(28)$ & 0.088 \\
\hline Complete & $0(0)$ & $1(4)$ & 7 (16) & $12(18)$ & 0.071 \\
\hline \multicolumn{6}{|l|}{ Clinical outcome at 3 months } \\
\hline mRS score $0-1, \mathrm{n}$ & $0 / 16(0)$ & $5 / 14(36)$ & $12 / 25(48)$ & $13 / 40(33)$ & 0.014 \\
\hline
\end{tabular}

Figures in parentheses are percentages or interquartile ranges. M1 indicates the horizontal portion of the MCA, M2 the sylvian portion of the MCA. ASPECTS = Alberta Stroke Program Early Computed Tomography Score.

An SVS was seen in 91 (58\%) of the 158 patients. M1 proximal SVS (M1 proximal group) was seen in 25 (16\%) patients; M1 distal SVS (M1 distal group) in 22 (14\%); MCA distal SVS (MCA distal group) in 44 (28\%), and 67 (42\%) patients did not have an SVS (No SVS group). The patients' clinical characteristics and imaging findings according to the SVS locations are shown in table 1 . The NIHSS score of the M1 proximal group was the highest $(p=0.001)$. The incidence of hypertension was significantly different among the 4 groups $(p=0.037)$. Regarding the sites of arterial occlusions, ICA occlusion was frequent (72\%) in the M1 proximal group ( $\mathrm{p}<0.001)$, M1 occlusion was frequent $(86 \%)$ in the M1 distal group $(\mathrm{p}<$ $0.001)$, and M2 occlusion was frequent $(52 \%)$ in the MCA distal group ( $p<0.001)$. The No SVS group had ICA occlusion more frequently than the MCA distal group (27 vs. 9\%, $\mathrm{p}=0.028$ ).

Early recanalization occurred in 57 (36\%) patients (table 2). On univariate analysis, M1 proximal SVS was seen in $24(24 \%)$ of the 101 patients with no early recanalization and in 1 

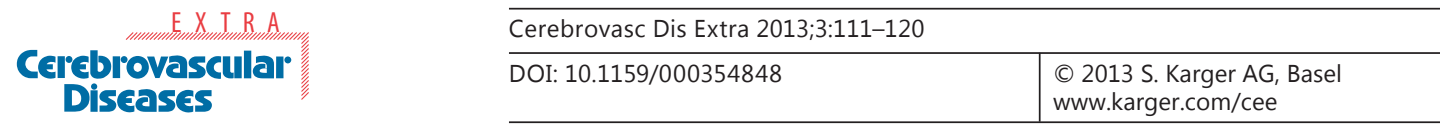

Aoki et al.: Location of the Susceptibility Vessel Sign on T2*-Weighted MRI and Early Recanalization within 1 Hour after Tissue Plasminogen Activator Administration

Table 2. Clinical characteristics and imaging findings between patients with early recanalization and those with no early recanalization

\begin{tabular}{|c|c|c|c|}
\hline Variables & $\begin{array}{l}\text { Early } \\
\text { recanalization } \\
(\mathrm{n}=57)\end{array}$ & $\begin{array}{l}\text { No early } \\
\text { recanalization } \\
(\mathrm{n}=101)\end{array}$ & $\mathrm{p}$ \\
\hline Median age, years & $78(73-84)$ & $78(71-84)$ & 0.710 \\
\hline Male sex, $\mathrm{n}$ & $33(58)$ & $51(51)$ & 0.409 \\
\hline Median NIHSS score on admission & $15(10-20)$ & $17(11-20)$ & 0.420 \\
\hline mRS score $0-1, n$ & $41(74)$ & $77(76)$ & 0.848 \\
\hline Interval from onset to thrombolysis, min & $132(113-166)$ & $153(125-170)$ & 0.107 \\
\hline Intra-arterial intervention, $\mathrm{n}$ & $3(5)$ & $20(20)$ & 0.017 \\
\hline \multicolumn{4}{|l|}{ Susceptibility vessel sign, $\mathrm{n}$} \\
\hline M1 proximal & $1(2)$ & $24(24)$ & $<0.001$ \\
\hline M1 distal & $6(11)$ & $16(16)$ & 0.474 \\
\hline MCA distal & $19(33)$ & $25(25)$ & 0.271 \\
\hline No SVS & $31(54)$ & $36(36)$ & 0.029 \\
\hline \multicolumn{4}{|l|}{ Vascular risk factor, $\mathrm{n}$} \\
\hline Hypertension & $19(33)$ & $33(33)$ & 1.000 \\
\hline Diabetes mellitus & $45(79)$ & $81(80)$ & 0.840 \\
\hline Hyperlipidemia & $48(84)$ & 77 (76) & 0.309 \\
\hline Atrial fibrillation & $27(47)$ & $39(39)$ & 0.316 \\
\hline \multicolumn{4}{|l|}{ Past medication, $\mathrm{n}$} \\
\hline Antiplatelet therapy & $14(25)$ & $26(26)$ & 1.000 \\
\hline Anticoagulation therapy & $5(9)$ & $11(11)$ & 0.788 \\
\hline Median systolic blood pressure, mm Hg & $132(113-166)$ & $152(136-167)$ & 0.406 \\
\hline Median diastolic blood pressure, $\mathrm{mm} \mathrm{Hg}$ & $80(70-90)$ & $84(71-96)$ & 0.256 \\
\hline \multicolumn{4}{|l|}{ Stroke etiology, $\mathrm{n}$} \\
\hline Large-artery atherosclerosis & $2(4)$ & $14(14)$ & 0.053 \\
\hline Cardioembolism & $32(56)$ & $66(65)$ & 0.306 \\
\hline Other or undetermined & $23(40)$ & $21(21)$ & 0.010 \\
\hline \multicolumn{4}{|l|}{ Portion of occlusion, $\mathrm{n}$} \\
\hline ICA & $8(14)$ & $35(35)$ & 0.005 \\
\hline M1 & $30(53)$ & $39(39)$ & 0.097 \\
\hline M2 & $19(33)$ & $27(27)$ & 0.466 \\
\hline \multicolumn{4}{|l|}{ DWI findings } \\
\hline Median ASPECTS & $8(5-10)$ & $8(6-9)$ & 0.828 \\
\hline Median initial ischemic volume, $\mathrm{ml}$ & $5.6(1.0-39.2)$ & $9.4(1.9-37.2)$ & 0.588 \\
\hline
\end{tabular}

Figures in parentheses are percentages or interquartile ranges. M1 indicates the horizontal portion of the MCA, M2 the sylvian portion of the MCA. ASPECTS = Alberta Stroke Program Early Computed Tomography Score.

$(2 \%)$ of the 57 patients with early recanalization $(\mathrm{p}<0.001)$. On the other hand, No SVS was more frequent in the early recanalization group than in the no early recanalization group (54 vs. $36 \%, p=0.029$ ). ICA occlusion was less frequently observed in patients in the early recanalization group than in those not in the early recanalization group (14 vs. $35 \%, \mathrm{p}=0.005$ ).

The rates of no early recanalization among the 4 groups are shown in figure 2 . Twentyfour (96\%) of the 25 patients in the M1 proximal group, 16 (73\%) of the 22 patients in the M1 distal group, 25 (57\%) of the 44 patients in the MCA distal group, and 36 (54\%) of the 67 patients in the No SVS group had no early recanalization $(p<0.001)$. The frequency of no early recanalization was significantly higher in the M1 proximal group than in the M1 distal group, the MCA distal group, and the No SVS group ( $p=0.040,0.001$, and $<0.001$, respectively). On the other hand, the rate of no early recanalization in the M1 distal group was not different 


\section{Cerebirovascular \\ Diseases}

Table 3. Multivariate logistic regression analysis for factors associated with no early recanalization

\begin{tabular}{|c|c|c|c|}
\hline \multicolumn{4}{|l|}{ Cerebrovasc Dis Extra 2013;3:111-120 } \\
\hline \multicolumn{2}{|l|}{ DOI: $10.1159 / 000354848$} & \multicolumn{2}{|l|}{$\begin{array}{l}\text { (C) } 2013 \text { S. Karger AG, Basel } \\
\text { www.karger.com/cee }\end{array}$} \\
\hline \multicolumn{4}{|c|}{$\begin{array}{l}\text { Aoki et al.: Location of the Susceptibility Vessel Sign on T2*-Weighted MRI and Early } \\
\text { Recanalization within } 1 \text { Hour after Tissue Plasminogen Activator Administration }\end{array}$} \\
\hline Parameters & $\begin{array}{l}\text { Odds } \\
\text { ratio }\end{array}$ & $\begin{array}{l}95 \% \text { Confidence } \\
\text { interval }\end{array}$ & $\mathrm{p}$ \\
\hline \multicolumn{4}{|l|}{ Susceptibility vessel sign } \\
\hline M1 proximal & 16.80 & $2.04-138.17$ & 0.009 \\
\hline M1 distal & 2.93 & $0.92-9.34$ & 0.070 \\
\hline MCA distal & 1.23 & $0.55-2.79$ & 0.615 \\
\hline \multicolumn{4}{|l|}{ Stroke etiology } \\
\hline Large-artery atherosclerosis & 2.64 & $0.51-13.73$ & 0.250 \\
\hline Other or undetermined & 0.56 & $0.26-1.20$ & 0.134 \\
\hline \multicolumn{4}{|l|}{ Portion of the arterial occlusion } \\
\hline ICA & 1.21 & $0.39-3.71$ & 0.744 \\
\hline M1 & 0.6 & $0.26-1.41$ & 0.242 \\
\hline
\end{tabular}

Fig. 2. Incidences of no early recanalization based on the presence of the SVS.

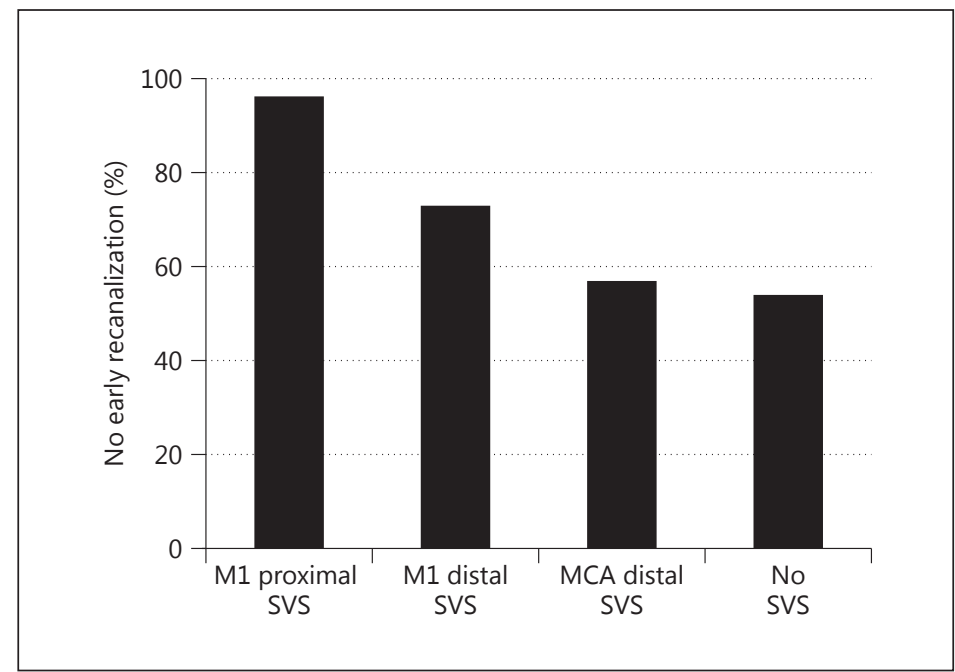

from that in the MCA distal group and in the No SVS group ( $p=0.284$ and 0.140 , respectively). No significant difference in the rate of no early recanalization was seen between the MCA distal group and the No SVS group ( $\mathrm{p}=0.846)$.

Multivariate analysis showed that only M1 proximal SVS was significantly associated with no early recanalization after adjusting for M1 distal SVS, MCA distal SVS, stroke etiologies (large-artery atherosclerosis and other or undetermined), ICA occlusion, and M1 occlusion (odds ratio, 16.80; 95\% confidence interval, 2.04-138.17; $\mathrm{p}=0.009$; table 3).

At 3 months, 95 patients with premorbid mRS scores of $0-1$ and without intra-arterial intervention were eligible for the assessment of clinical outcome (fig. 3). None (0\%) of the M1 proximal group, $36 \%$ of the M1 distal group, $48 \%$ of the MCA distal group, and 33\% of the No SVS group achieved good outcomes at 3 months $(p=0.014)$. Therefore, the M1 proximal group obtained a significantly lower rate of good outcome than the M1 distal group, the MCA distal group, and the No SVS group ( $p=0.014,0.001$, and 0.011 , respectively). However, no significant difference in the rate of good outcome was seen between the M1 distal group and the No SVS group, nor between the MCA distal group and the No SVS group ( $p=1.000$ and 0.295 , respectively). 


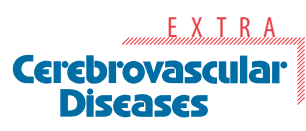

Fig. 3. Distribution of the mRS score at 3 months after stroke onset based on the presence of the SVS. Numbers of patients are given in the bars.

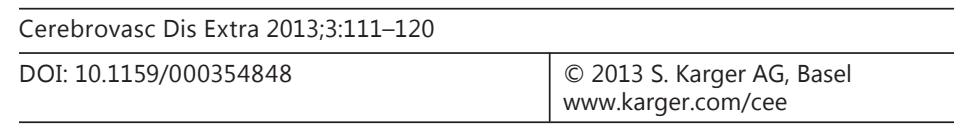

Aoki et al.: Location of the Susceptibility Vessel Sign on T2*-Weighted MRI and Early Recanalization within 1 Hour after Tissue Plasminogen Activator Administration

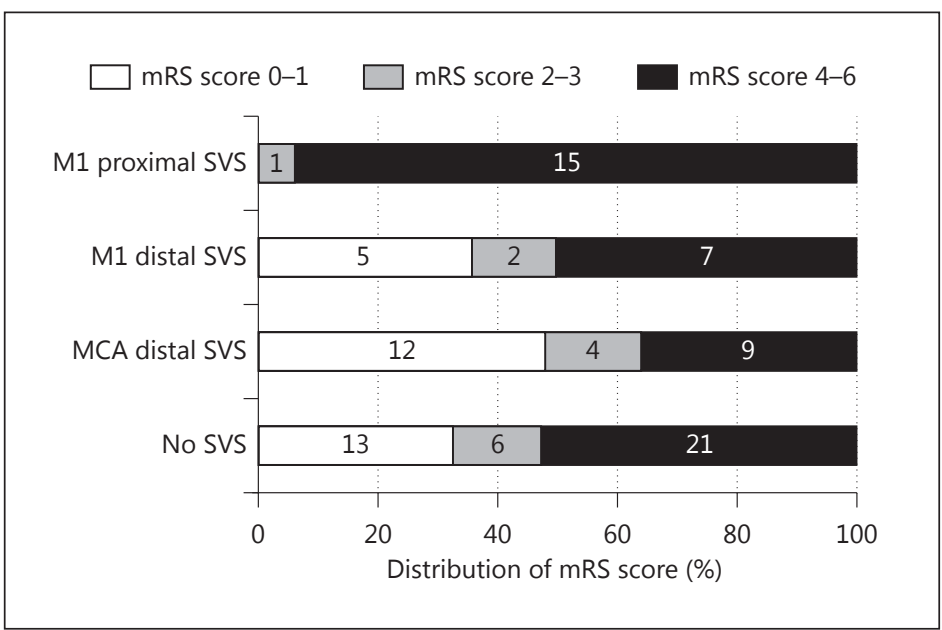

\section{Discussion}

The present study demonstrated that $96 \%$ of the patients with M1 proximal SVS had no early recanalization after t-PA therapy. Furthermore, no patients with M1 proximal SVS achieved a good outcome at 3 months. On the other hand, neither the rates of early recanalization nor good outcome was different among patients with M1 distal SVS, MCA distal SVS, and No SVS.

Recently, we have reported that the presence of an SVS on T2*-weighted MRI was associated with resistance to t-PA therapy. The magnetic susceptibility effect of deoxygenated hemoglobin in red thrombi may result in hypointense signals on T2*-weighted MRI. Cho et al. [16] reported that red thrombi in occluded vessels were visualized as hypointense signals within vascular cisterns on T2*-weighted MRI. They called such radiological findings the 'SVS'. The SVS may reflect thrombus composition. Hemoglobin desaturation from oxyhemoglobin to deoxyhemoglobin occurs within a few hours. Thus, in hyperacute clot cases, the main component may still be oxyhemoglobin, and such emboli would not be identified as SVS on T2*-weighted MRI. In other words, the SVS is present in older thrombi, which may be resistant to t-PA therapy.

In the present study, the early recanalization rate of M1 distal SVS and MCA distal SVS was about 50\%, which was higher than that of M1 proximal SVS. In general, when a small thrombus occludes the distal artery, the embolus volume of M1 proximal SVS may be largest among M1 proximal, M1 distal, and MCA distal SVS. When a thrombus is small, the proportion of the area in contact with t-PA becomes larger compared to a large thrombus, and thus t-PA may be more effective for smaller emboli. Therefore, M1 proximal SVS is the most resistant to $\mathrm{t}-\mathrm{PA}$, and its early recanalization rate should be the lowest.

Early recanalization by t-PA administration can improve patient outcomes [2]. None of the patients with M1 proximal SVS achieved a good outcome 3 months after onset. We strongly presume that this is because t-PA cannot dissolve the M1 proximal SVS thrombus. Furthermore, the NIHSS score was higher in the M1 proximal group than in the other groups. Neurological severity before t-PA infusion affects patient outcome [17]. Therefore, patients with M1 proximal SVS most frequently had a poor outcome. After the Merci retriever and Penumbra aspiration systems were approved, the combination of t-PA therapy and intra-arterial intervention has attracted significant attention, because this combination therapy significantly increases the early recanalization rate $[18,19]$. In the RECANALISE study, $87 \%$ of the patients 
treated with the combined intravenous and intra-arterial approach achieved recanalization, compared to only $52 \%$ of the patients treated with t-PA alone [4]. With respect to medical therapy, we previously showed that the administration of edaravone, a free radical scavenger, during t-PA therapy might increase the incidence of early recanalization [20]. For patients with M1 proximal SVS, an immediate combination of these therapies may be of benefit, and this should be initiated before judging whether t-PA will be effective or not.

No SVS did not necessarily indicate patients who achieved a good outcome, i.e. only $33 \%$ of the patients with No SVS had a good outcome. Our study showed that the rates of no early recanalization were not different among patients with M1 distal SVS, MCA distal SVS, and No SVS. Thus, this result may be explained by the ICA occlusion rate, which was higher in the order of patients with M1 proximal SVS, No SVS, M1 distal SVS, and MCA distal SVS. It is reasonable to consider that large-vessel occlusion damages larger tissue samples compared to small-vessel occlusion.

There are several limitations in the present study. First, the number of patients was small. Second, our T2* protocol included a slice thickness of $6 \mathrm{~mm}$ and an interslice gap of $1 \mathrm{~mm}$. If the artery was smaller than $6 \mathrm{~mm}$, it may have been difficult to detect a small SVS, especially in the MCA branches. Third, our study did not include detailed information on occluded ICA segments. It was difficult to distinguish ICA top occlusion from ICA occlusion at other intracranial segments, when the patients showed a diminished flow signal. Even patients with proximal ICA occlusion might have tandem ICA top occlusion. This may be clarified only when CT angiography or digital subtraction angiography is performed. In addition, it also seems to be potentially difficult to discriminate a thrombus from the blood stream on T2*-weighted MRI [21]. Thus, artery occlusion must be diagnosed on MRA to assess the SVS. Finally, a $0.6-\mathrm{mg} / \mathrm{kg}$ dose of t-PA was used, based on the Japan Alteplase Clinical Trial [8]. If the internationally recommended dose had been selected, the role of M1 proximal SVS might have been different. Further, large, prospective, randomized trials are required to confirm the utility of M1 proximal SVS in patients treated with intravenous thrombolysis.

In conclusion, M1 SVS at the proximal portion of the MCA, but not at other portions, is the critical determinant of no early recanalization and a poor outcome after t-PA therapy.

\section{Disclosure Statement}

The authors have no conflicts of interest to disclose.

\section{References}

1 Kimura K, Iguchi Y, Shibazaki K, Aoki J, Uemura J: Early recanalization rate of major occluded brain arteries after intravenous tissue plasminogen activator therapy using serial magnetic resonance angiography studies. Eur Neurol 2009;62:287-292.

-2 Kimura K, Iguchi Y, Shibazaki K, Aoki J, Watanabe M, Kobayashi K, Sakamoto Y: Recanalization within one hour after intravenous tissue plasminogen activator is associated with favorable outcome in acute stroke patients. Eur Neurol 2010;63:331-336.

-3 Yeo LL, Paliwal P, Teoh HL, Seet RC, Chan BP, Liang S, Venketasubramanian N, Rathakrishnan R, Ahmad A, Ng KW, Loh PK, Ong JJ, Wakerley BR, Chong VF, Bathla G, Sharma VK: Timing of recanalization after intravenous thrombolysis and functional outcomes after acute ischemic stroke. JAMA Neurol 2013;70:353-358.

4 Mazighi M, Serfaty JM, Labreuche J, Laissy JP, Meseguer E, Lavallee PC, Cabrejo L, Slaoui T, Guidoux C, Lapergue B, Klein IF, Olivot JM, Abboud H, Simon O, Niclot P, Nifle C, Touboul PJ, Raphaeli G, Gohin C, Claeys ES, Amarenco $P$ : Comparison of intravenous alteplase with a combined intravenous-endovascular approach in patients with stroke and confirmed arterial occlusion (RECANALISE study): a prospective cohort study. Lancet Neurol 2009;8:802-809.

-5 Kimura K, Iguchi Y, Shibazaki K, Watanabe M, Iwanaga T, Aoki J: M1 susceptibility vessel sign on T2* as a strong predictor for no early recanalization after IV-t-PA in acute ischemic stroke. Stroke 2009;40:3130-3132. 
Aoki et al.: Location of the Susceptibility Vessel Sign on T2*-Weighted MRI and Early Recanalization within 1 Hour after Tissue Plasminogen Activator Administration

6 Kimura K, Sakamoto Y, Aoki J, Iguchi Y, Shibazaki K, Inoue T: Clinical and MRI predictors of no early recanalization within $1 \mathrm{~h}$ after tissue-type plasminogen activator administration. Stroke 2011;42:3150-3155.

7 Rovira A, Orellana P, Alvarez-Sabin J, Arenillas JF, Aymerich X, Grive E, Molina C, Rovira-Gols A: Hyperacute ischemic stroke: middle cerebral artery susceptibility sign at echo-planar gradient-echo MR imaging. Radiology 2004;232:466-473.

8 Yamaguchi T, Mori E, Minematsu K, Nakagawara J, Hashi K, Saito I, Shinohara Y: Alteplase at $0.6 \mathrm{mg} / \mathrm{kg}$ for acute ischemic stroke within $3 \mathrm{~h}$ of onset: Japan alteplase clinical trial (J-ACT). Stroke 2006;37:1810-1815.

$\checkmark 9$ Shinohara Y, Yamaguchi T: Outline of the Japanese guidelines for the management of stroke 2004 and subsequent revision. Int J Stroke 2008;3:55-62.

10 Aoki J, Kimura K, Iguchi Y, Shibazaki K, Iwanaga T, Watanabe M, Kobayashi K, Sakai K, Sakamoto Y: Intravenous thrombolysis based on diffusion-weighted imaging and fluid-attenuated inversion recovery mismatch in acute stroke patients with unknown onset time. Cerebrovasc Dis 2011;31:435-441.

11 Adams HP Jr, Bendixen BH, Kappelle LJ, Biller J, Love BB, Gordon DL, Marsh EE 3rd: Classification of subtype of acute ischemic stroke. Definitions for use in a multicenter clinical trial. TOAST. Trial of Org 10172 in Acute Stroke Treatment. Stroke 1993;24:35-41.

12 Barber PA, Demchuk AM, Zhang J, Buchan AM: Validity and reliability of a quantitative computed tomography score in predicting outcome of hyperacute stroke before thrombolytic therapy. ASPECTS Study Group. Alberta Stroke Programme Early CT Score. Lancet 2000;355:1670-1674.

-13 Barber PA, Hill MD, Eliasziw M, Demchuk AM, Pexman JH, Hudon ME, Tomanek A, Frayne R, Buchan AM: Imaging of the brain in acute ischaemic stroke: comparison of computed tomography and magnetic resonance diffusion-weighted imaging. J Neurol Neurosurg Psychiatry 2005;76:1528-1533.

14 Turc G, Apoil M, Naggara O, Calvet D, Lamy C, Tataru AM, Meder JF, Mas JL, Baron JC, Oppenheim C, Touze E: Magnetic resonance imaging-DRAGON score: 3-month outcome prediction after intravenous thrombolysis for anterior circulation stroke. Stroke 2013;44:1323-1328.

-15 Higashida RT, Furlan AJ, Roberts H, Tomsick T, Connors B, Barr J, Dillon W, Warach S, Broderick J, Tilley B, Sacks D: Trial design and reporting standards for intra-arterial cerebral thrombolysis for acute ischemic stroke. Stroke 2003;34:e109-e137.

16 Cho KH, Kim JS, Kwon SU, Cho AH, Kang DW: Significance of susceptibility vessel sign on T2*-weighted gradient echo imaging for identification of stroke subtypes. Stroke 2005;36:2379-2383.

-17 Frankel MR, Morgenstern LB, Kwiatkowski T, Lu M, Tilley BC, Broderick JP, Libman R, Levine SR, Brott T: Predicting prognosis after stroke: a placebo group analysis from the National Institute of Neurological Disorders and Stroke rt-PA Stroke Trial. Neurology 2000;55:952-959.

-18 Smith WS, Sung G, Starkman S, Saver JL, Kidwell CS, Gobin YP, Lutsep HL, Nesbit GM, Grobelny T, Rymer MM, Silverman IE, Higashida RT, Budzik RF, Marks MP: Safety and efficacy of mechanical embolectomy in acute ischemic stroke: results of the MERCI trial. Stroke 2005;36:1432-1438.

19 Bose A, Henkes H, Alfke K, Reith W, Mayer TE, Berlis A, Branca V, Sit SP: The penumbra system: a mechanical device for the treatment of acute stroke due to thromboembolism. AJNR Am J Neuroradiol 2008;29:14091413.

20 Kimura K, Aoki J, Sakamoto Y, Kobayashi K, Sakai K, Inoue T, Iguchi Y, Shibazaki K: Administration of edaravone, a free radical scavenger, during t-PA infusion can enhance early recanalization in acute stroke patients - A preliminary study. J Neurol Sci 2012;313:132-136.

21 Teitelbaum GP, Ortega HV, Vinitski S, Clark RA, Watanabe AT, Matsumoto AH, Rifkin MD, Barth KH: Optimization of gradient-echo imaging parameters for intracaval filters and trapped thromboemboli. Radiology 1990;174:1013-1019. 